\title{
The Effect of Positive Evidence and Negative Feedback on EFL Learners' Acquisition of the Third Person Singular Form
}

\author{
Lin Jiang ${ }^{1} \&$ Huiwen $\mathrm{Yi}^{2}$ \\ ${ }^{1}$ Faculty of English Language \& Culture, Guangdong University of Foreign Studies, Guangzhou, China \\ ${ }^{2}$ Dongguan No. 6 Senior High School, Dongguan, China \\ Correspondence: Lin Jiang, Faculty of English Language \& Culture, Guangdong University of Foreign Studies, \\ Guangzhou, 510420, China. E-mail: jlin@gdufs.edu.cn
}

\author{
Received: September 26, 2014 Accepted: October 30, 2014 Online Published: November 25, 2014 \\ doi:10.5539/ijel.v4n6p124 \\ URL: http://dx.doi.org/10.5539/ijel.v4n6p124
}

\begin{abstract}
The study compared the relative effectiveness of two types of input situated in written context - positive evidence and negative feedback — on Chinese lower intermediate EFL learners' acquisition of the third person singular form. Using a pretest-posttest and control group experimental design, the effect of these two types of input was measured by an error correction test and a speeded dictation test. In addition, a retrospective interview conducted at the end of the study provided information about the use that they made of the two types of input. It was found that both treatment groups performed much better than the control group on the immediate and delayed posttests, but no significant differences were found between the two treatment groups. The results indicated that positive evidence and negative feedback facilitated L2 acquisition of the third person singular form to the same extent. These results were discussed from the perspective of cognitive psychology and suggestions for further research are put forward.
\end{abstract}

Keywords: positive evidence, negative feedback, third person singular form, attention

\section{Introduction}

In many approaches to second language acquisition (SLA), input is seen as being a highly important factor in acquisition. According to Gass (1997), language learners have access to two types of input: positive evidence and negative evidence. Positive evidence comprises "the set of well-formed sentences to which learners are exposed" (p. 36), which informs the learner of what is acceptable in the target language. In some SLA literature, positive evidence is also referred to as models and viewed as the most direct means that learners have available to them from which they can form linguistic hypothesis (Gass, 2003). By comparison, Negative evidence, also known as "negative feedback", provides the learner with information about the incorrectness of a second language (L2) form and is often realized through the provision of corrective feedback (CF) in response to the learner's non-target like L2 production. Given the distinction between the two types of input, one question arises: which type of evidence is more beneficial for L2 acquisition. However, the currently available evidence is far from conclusive and that a body of well-designed studies is needed if this key issue is to be resolved. Thus, the present study aims at investigating the relative effectiveness of positive evidence and negative feedback on Chinese EFL learners' acquisition of the third person singular form, which can contribute to the SLA research on input, both theoretically and empirically.

\section{Literature Review}

\subsection{Studies on Negative Evidence}

"Positive evidence is the most obviously necessary requirement for learning. One must have exposure to the set of grammatical sentences in order for learning to take place" (Gass, 2003, p. 226). Mackey (2007) made a research synthesis of 75 studies on input and interaction. It was found that 51 of them focused on negative evidence, and only four of them involved positive evidence. This research bias is largely due to the fact that positive evidence is too common a factor to be explored thoroughly. In this section, we survey theory and research on negative evidence.

In L2 acquisition theories, the role of negative evidence remains in great dispute historically. In the 1950s and 1960s, behaviorist perspective of language learning which emphasized habit formation hold the view that 
negative feedback is necessary because errors were damaging to language learning and must be eradicated. Latter in the 1970s and 1980s, believing in the sufficiency of comprehensible input (i.e., positive evidence), nativism saw little to no role for a focus on error and its treatment in this process. In the 1990s, interactional perspective has begun to explore the effects of some interactional moves on L2 development and claimed that exposure to the model of positive evidence alone is not sufficient for L2 development and that learners need to be 'pushed' to produce modified output in oral interactions. In other words, negative feedback has an important role to play in the process of SLA. More recently, Truscott, in a series of papers, consistently argued that error correction is ineffective and even harmful and should therefore be abandoned (e.g., Truscott, 1996, 1999, 2009). His justification for this position was based on theoretical, empirical, and pedagogical arguments, many of which he continues to maintain despite the range of counter-arguments and the growing empirical evidence.

Given that the role of negative evidence in language acquisition was theoretically unestablished, a great number of empirical studies on its effectiveness have been provoked and researchers have approached the issue from varied perspectives. Some studies focused on oral negative evidence, while others investigated written negative evidence. Some examined the explicit negative evidence, directing participants' attention to forms, whereas others were concerned with the effectiveness of implicit negative evidence. Some investigated the extent to which individual factors (e.g., language analytic ability, anxiety and learners' attitudes, etc.) might influence learners' engagement with the CF they are given, while others were interested in the potential influence of contextual factors. Some studies were conducted from SLA perspective, concerned with whether CF has any impact on interlanguage development, whereas others examined CF from L2 writing perspective, focusing on whether error correction truly makes students more successful writers. In sum, it is important to understand that although researchers looked at the same topic (i.e., negative evidence), they examined it in distinct ways. Nevertheless, As a body of work, they reported compelling and robust evidence that negative feedback, under the right conditions, can benefit L2 development, indicating that there may be value both in teachers' continuing to provide CF carefully and in making further efforts to conduct studies that address some of the unresolved questions.

\subsection{Studies on Comparing Positive Evidence and Negative Feedback}

Over the last three decades, comparing the relative effects of positive evidence and negative feedback has been prominent in the literature of L2 acquisition. However, the existing studies all investigated the short-term impact of the two input types through two interactional moves - recasts and models-on L2 development. As an implicit negative feedback, recasts refer to those instances in which an interlocutor rephrases an incorrect utterance with a corrected version, while maintaining the integrity of the original meaning (Gass, 2003). The following example taken from Philp (1999, p. 92) illustrates the form that a recast takes. In the example, it is, of course, possible that the learner will not understand that this is intended as a correction and may only think that the speaker really did not hear what was said.

(1) NNS: * What doctor say?

\section{NS: What is the doctor saying? (recast)}

Building on experimental studies conducted in child first languageacquisition research, Mito (1993), Ortega and Long (1997), Long, Inagaki, and Ortega (1998), Inagaki and Long (1999), Ayoun (2001), and Iwashita (2003) compared the short-term effects of these two interactional moves on L2 acquisition of target grammatical structures. Summarizing the findings of these studies, more advantages for learning were reported under the recast condition than under the modeling condition, but in each of the studies, no learning was reported under either condition for at least one of the target structures. For example, Iwashita (2003) examined the short-term effects of positive evidence and negative feedback on the acquisition of two Japanese structures. It was found that although positive evidence moves about the target structures made by native speaker interlocutors were far more frequent than negative feedback moves during task-based interaction, only learners who had an above-average score on the pretest benefited from the positive evidence provided. However, negative feedback can facilitate the acquisition of the grammatical targets regardless of the learner's current mastery of the target structures. Nevertheless, clear evidence for the facilitative role of negative feedback was found for only one of the target structures. Long et al. (1998), referring specifically to these comparative studies, discussed the difficulties of investigating the short-term effects of L2 negative feedback: They argued that short-term cross-sectional studies cannot address the methodological difficulties they identified, and they proposed refinements to future studies, including delayed posttests and a longitudinal design. While these studies reported an advantage for negative feedback (viz., recasts) over positive evidence, other studies (Rabie, 1996) found no such advantage. 
Employing a pretest-posttest and control group experimental design similar to that of the studies discussed above, Rabie (1996) investigated the effectiveness of positive evidence and negative feedback (viz., recasts) on vocabulary learning. Her findings showed that NS conversation partners provided abundant CF on the target vocabulary in the process of task-based interaction. Participants learned the highest percentage of the target vocabulary items when the requested model (i.e., the model that was supplied by the NS in response to a NNS request) was given, followed by recasts and models that were not requested. Summarizing her findings, Rabie argued that the provision of models versus recasts had differential effects on the acquisition of the new vocabulary.

In the above comparative studies, recasts were all treated as a form of negative feedback. However, Leeman (2003) points out that recasts not only offer implicit negative evidence but also provide positive evidence, informing the learner of what is acceptable in the target language. To this end, he conducted a study to isolate the effect of positive evidence from negative evidence in recasts on the acquisition of noun-adjective agreement in Spanish. 74 participants were divided into four groups: recast group, negative feedback group, positive evidence group and control group. The results showed that the recast group and the positive evidence group performed much better than the control group, whereas the negative feedback group just failed to do so. This finding suggested that the effect of recasts was partly attributable to the positive evidence and that the negative evidence in recasts may not be a crucial factor for language acquisition.

Overall, it can be seen that the currently available evidence on the relative effectiveness of positive evidence and negative feedback is far from conclusive. Further research into this issue is therefore required. Moreover, the existing literature mainly focused on oral input in interlocutory context. In contrast, there has been very little consideration of written input in comparative studies. In terms of negative feedback, there are actually a number of ways in which oral and written feedback potentially differ. For example, some oral feedback strategies (e.g., recasts) are in the form of implicit information and their corrective force may not be noticed, while written feedback is more likely to be noticed by the learner as correction. Second, oral feedback is provided instantaneously to learners, whereas written feedback is delayed. Therefore, it is reasonable to predict that written feedback might be more beneficial for learning than oral feedback given that the former could enhance the learner's noticing of linguistic forms more easily, but in the meantime imposes less cognitive load on the short-term memory of the learners than the latter. To this end, the present study intends to fill that gap by investigating the relative effectiveness of positive evidence and negative feedback situated in the written context on the acquisition of the third person singular form.

\subsection{Studies on L2 Acquisition of the Third Person Singular Form}

In the case of the third person singular form, the failure to achieve L2 accuracy has been well documented in the SLA literature (e.g., Bailey, Madden, \& Krashen, 1974; Dulay \& Burt, 1974; Ellis, 1988; Johnson \& Newport, 1989; Perkins \& Larsen-Freeman, 1975; Shapira, 1978; Wei, 2000). Larsen-Freeman (2009) referred this inflectional problem as the "inert knowledge problem"-- that is, learners can understand and express the grammatical rules of the structure, but cannot use it for effective problem-solving in realistic situations. In general, most of the early SLA studies on the structure were descriptive in nature, often analyzing L2 output to see whether improved accuracy has taken place as learners were exposed to more target input. For example, Lardiere (1998) conducted an 8-year longitudinal study investigating interlanguage development of a Chinese EFL learner who was married to an English native speaker and lived in the United States for more than 20 years. It was found that even after many years of exposure to the target language, her knowledge of the third person singular form was still grammatically flawed.

In recent years, a growing number of studies have concentrated on addressing why the third person singular form imposed such a difficulty for L2 learners. Jiang (2004) found that during sentence processing, Chinese learners of English tended to focus on the plurality of the subject rather than the verb, suggesting that their morphological knowledge is not part of their L2 competence. Some studies (Ellis \& Sagarra, 2010; Haznedar, 2001; Ionin \& Wexler, 2002; Paradis, Rice, Crago, \& Marquis, 2008) explored the learning difficulty from the perspective of cognitive psychology and argued that earlier learned language cues (i.e., the plural form of the subject) blocked the acquisition of later experienced ones (i.e., the less salient verb morphology). Wang (2011) proposed that the high frequency of inflectional errors might be due to the deficiency of language experience and stimulus to trigger the already-known rules in the representation of learners' knowledge. Blom, Paradis, and Duncan (2012) examined a wide range of factors by applying linear mixed effects modeling in the framework of usage-based approach. The results showed that word frequency, allomorph, lexicon size, inflectional properties of the L1 and duration of exposure to English all have impact on the acquisition of the third person singular form. In sum, SLA research of the third person singular form laid much attention on analyzing learners' errors. However, there has 
been no consideration into how this inflectional morpheme has been acquired. The present study intends to fill that gap by investigating the relative effectiveness of two types of input on Chinese EFL learners' acquisition of the third person singular form.

\subsection{Research Questions}

In light of the gaps identified in the literature review, the following two research questions motivated the present study:

- Do positive evidence and negative feedback have an effect on Chinese EFL learners' acquisition of the third person singular form?

- Is there any difference in the efficacy that positive evidence and negative feedback have on L2 acquisition of this inflectional morpheme?

\section{The Study}

\subsection{Participants}

The participants were 125 low-intermediate students from three intact 1st-year English classes in a junior college in China. All participants were Chinese speakers who have learnt English in China for nearly 6 years. In the college, they received a ninety-minute instruction on English by the same teacher twice a week. After eliminating students who were absent from any phase of the study, the number of participants reached 82, including 51 female and 31 male students aged 18-21. An English proficiency test, namely the Quick Placement Test (UCLES, 2001) was administrated to participants. A one-way ANOVA showed that there was no significant difference among the three classes $(p>.05)$ and that they were all at the lower intermediate level. The three intact classes were randomly assigned as positive evidence (PE) group $(n=30)$, negative feedback (NF) group $(n=28)$, and control group $(n=24)$.

\subsection{Research Design}

The study used a pretest-treatment-immediate posttest-delayed posttest research design, and lasted for a period of seven weeks with an interval of four weeks between the immediate posttest (Posttest 1) and the delayed posttest (Posttest 2) when the three groups took normal classes. Pretest was administered in week 1 . The treatment sessions took place in week 2 and 3. Posttest 1 was conducted immediately after the treatment session. Four weeks later, that is, in week 7, participants took Posttest 2 which was followed by a retrospective interview. Each testing session consisted of two subtests: an error correction test and a speeded dictation test.

\subsection{Treatment Procedure}

The study comprised of two treatment sessions, which are in the same form. Take session 1 as an example, the treatment procedure is illustrated as follows.

The PE group was first asked to read an essay about the daily life of an American fresh student. In the essay the verbs with third person singular form and some useful expressions were underlined. Before asking the students to write an essay about the daily life of their own roommates, the teacher discussed the content of the sample essay with the class. In the following week, the students received feedback on their essay, which was just a general comment such as "a good essay" or "an impressive writing".

The NF group was required to write an essay with the topic "The Daily Life of My Roommate" in class and received written $\mathrm{CF}$ in the following week. The feedback was operationalized as underlining the errors without explicit correction, as shown in (2). The students were asked to look over the teacher's feedback carefully for 10 minutes. Apart from the third person singular form, feedback on other linguistic errors were also given so as to cover the focus of the study and prevent students from consciously monitoring the use of this inflectional morpheme in posttests.

(2) * She always get up early in the morning.

The control group wrote an essay about the daily life of their roommates only, and did not receive any type of input, namely positive evidence or negative feedback.

\subsection{Instruments}

\subsubsection{Error Correction Test}

This test consisted of 20 items with one and only one error in each item. Learners were instructed to locate the error and make correction without time limit. Among the 20 items, 10 items involve the use of the third person singular form and the other 10 items were distracters involving the use of articles, subjunctive mood, 
prepositions, and so on. The example below is taken from the test.

(3) * Some students find that doing a part-time job provide a welcome break from academic work, and a good opportunity to develop friends from outside of university.

Learners were assigned one point for each correct suppliance of the third person singular form in the 10 obligatory contexts in the test. Distracters were not included in scoring, so the perfect score for this test was 10 points. The same testing materials were used for the pretest, Posttest 1, and Posttest 2, but the order of the items was randomly changed from one testing session to another.

\subsubsection{Speeded Dictation Test}

In the test, the participants were required to complete 15 blanks in a passage based on what they heard in the tape. Among the 15 blanks, 10 were involved with the verbs ended with the third person singular form. The other 5 blanks were distracters involving adverbs and nouns. The passage was played twice by a computer audio player. For the first time, it was played with normal speed so that the participants can get a general idea of the whole passage. For the second time it was played with 5 -second pause after each sentence. One point was given for each correct suppliance of the target verb with the third person singular form in the 10 obligatory contexts. Excluding the distracters, 10 points was the total score for the test.

The same passage "A Dish Washer" was used for the pretest and Posttest 1, but Posttest 2 was based on a different passage "Cows". The results of a pilot study involving a different group of low intermediate level students showed that there was no significant difference in the scores of the two passages, suggesting that the dictation tasks used for the two posttests were comparable.

\subsubsection{Retrospective Interview}

Ten participants in each treatment group were randomly chosen for a retrospective interview immediately following Posttest 2 to see if they had consciously noticed the target structure and how they dealt with the positive evidence or the negative feedback. The essays and testing papers completed in the study were returned to the participants for interview. The interview was conducted in Chinese and the list of questions is shown in Table 1.

Table 1. Retrospective interview questions

\begin{tabular}{ccl}
\hline \multirow{2}{*}{ Question 1 } & PE group & $\begin{array}{l}\text { Have you noticed the grammatical focus of the underlined sentences in the sample passages? If } \\
\text { you have, what is it? }\end{array}$ \\
\cline { 2 - 3 } & NF group & $\begin{array}{l}\text { Have you noticed the grammatical focus of the feedback provided to the errors in your writing? } \\
\text { If you have, what is it? }\end{array}$ \\
\cline { 2 - 3 } Question 2 & PE group & How did you deal with the sample passages when writing your own essay? \\
\cline { 2 - 3 } Question 3 & $\begin{array}{c}\text { NF group } \\
\text { treatment } \\
\text { groups }\end{array}$ & $\begin{array}{l}\text { How did you deal with the feedback provided to the errors in your writing? Which type of CF do } \\
\text { you favor? }\end{array}$ \\
\hline
\end{tabular}

\subsection{Test Reliability}

As for the error correction and speeded dictation tests, internal consistency reliability was estimated by calculating Cronbach's alpha. The reliability coefficient for the error correction pretest was $\alpha=0.79$, and for the speeded dictation pretest and posttest 1 was $\alpha=0.81$ and 0.84 , respectively.

\section{Results}

\subsection{Error Correction Test}

Descriptive statistics for the error correction test are presented in Table 2 and illustrated in Figure 1. It can be seen that both treatment groups showed a steady increase from pretest to Posttest 1, but a slight decrease from Posttest 1 to Posttest 2. The control group reported a gradual decrease from pretest to Posttest 1 but a dramatic increase from Posttest 1 to Posttest 2.

One-way ANOVAs with the posthoc tests revealed that there was no significant difference in accuracy rate among the three groups in pretest, $F(2,81)=0.73, p>.05$, and Posttest $2, F(2,81)=0.404, p>.05$, but significant differences were reported in Posttest $1, F(2,81)=6.095, p<.01$. Specifically, both treatment groups 
in Posttest 1 performed much better than the control group while no significant difference was found between the two treatment groups.

Table 2. Descriptive statistics for the error correction test

\begin{tabular}{lcccccc}
\hline \multirow{2}{*}{ Group } & \multicolumn{2}{c}{ Pretest } & \multicolumn{2}{c}{ Posttest 1 } & \multicolumn{2}{c}{ Posttest 2 } \\
\cline { 2 - 7 } & $\mathrm{M}$ & $\mathrm{SD}$ & $\mathrm{M}$ & $\mathrm{SD}$ & $\mathrm{M}$ & $\mathrm{SD}$ \\
\hline PE group & 6.07 & 2.29 & 7.00 & 2.26 & 6.94 & 2.42 \\
NF group & 5.86 & 2.83 & 7.07 & 2.54 & 6.68 & 2.81 \\
Control group & 5.46 & 2.80 & 5.00 & 2.42 & 6.25 & 2.61 \\
\hline
\end{tabular}

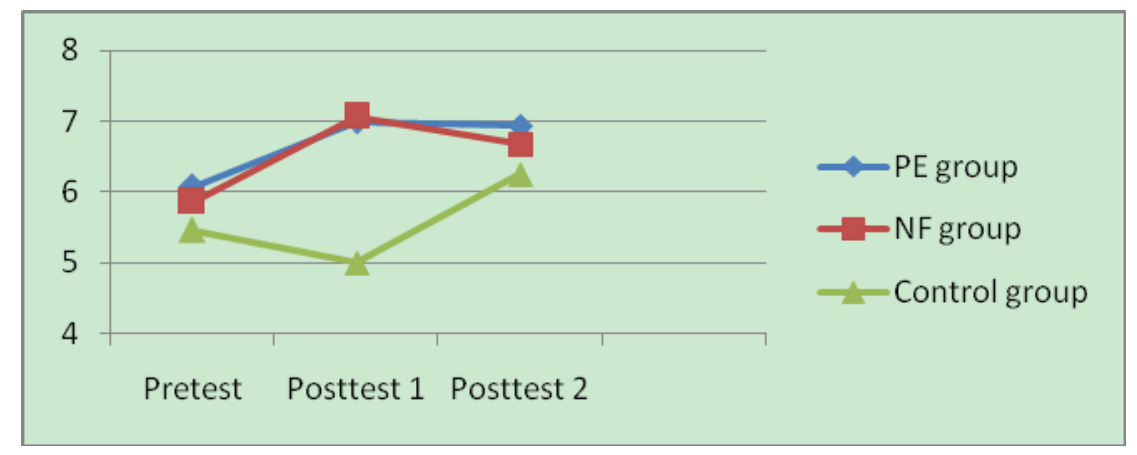

Figure 1. Group means on the error correction test

\subsection{Speeded Dictation Test}

Descriptive statistics for the speeded dictation test are presented in Table 3 and illustrated in Figure 2. It can be seen that the PE group showed a marked increase from pretest to Posttest 1, but a slight decrease from Posttest 1 to Posttest 2; The NF group showed consistent gains from pretest to posttests; The control group showed a small decrease from pretest to Posttest 1 while a slow increase from Posttest 1 to Posttest 2.

One-way ANOVAs with the posthoc tests revealed that there was no significant difference in accuracy rate among the three groups in pretest, $F(2,81)=2.473, p>.05$, but significant differences were reported in Posttest 1 , $F(2,81)=11.924, p<.001$, and Posttest $2, F(2,81)=12.231, p<.001$. Specifically, in Posttest $1 \& 2$ both treatment groups performed much better than the control group, but no significant difference was found between the two treatment groups.

Table 3. Descriptive statistics for the speeded dictation test

\begin{tabular}{lcccccc}
\hline \multirow{2}{*}{ Group } & \multicolumn{2}{c}{ Pretest } & \multicolumn{2}{c}{ Posttest 1 } & \multicolumn{2}{c}{ Posttest 2 } \\
\cline { 2 - 6 } & $\mathrm{M}$ & $\mathrm{SD}$ & $\mathrm{M}$ & $\mathrm{SD}$ & $\mathrm{M}$ & $\mathrm{SD}$ \\
\hline PE group & 3.35 & 1.91 & 5.39 & 2.29 & 5.35 & 2.05 \\
NF group & 3.61 & 1.70 & 4.77 & 2.73 & 5.47 & 2.36 \\
Control group & 2.54 & 1.77 & 2.42 & 1.69 & 2.98 & 1.50 \\
\hline
\end{tabular}

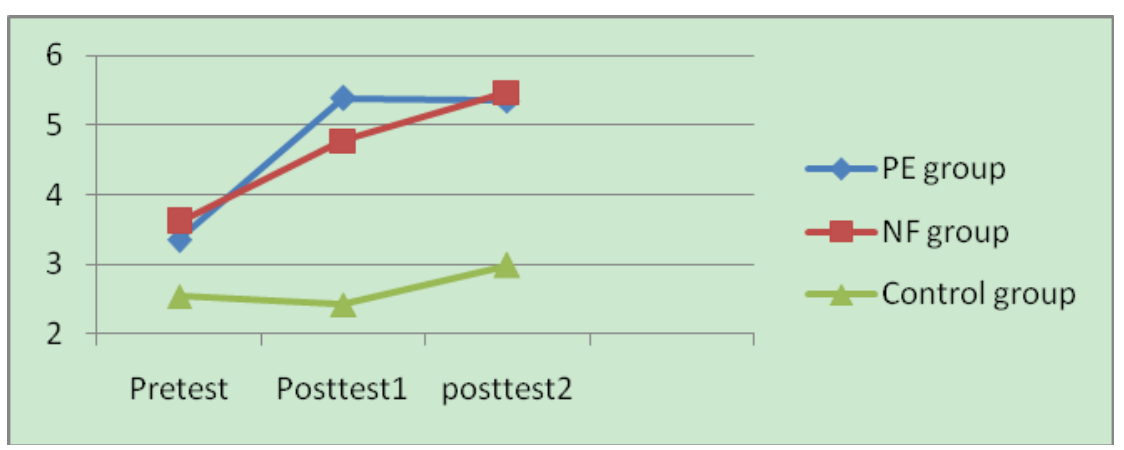

Figure 2. Group means on the speeded dictation test 


\subsection{Retrospective Interview}

In the case of Question 1, 45\% of the interviewed participants in the PE group noticed the grammatical focus of the underlined sentences in the sample passages, while the other 55\% thought the underlined sentences were just some good expressions for learning. In contrast, $90 \%$ of the interviewed participants in the NF group gave an affirmative answer, and only one participant did not find the focus of the feedback. When they talked about their errors in terms of the third person singular form, most of them expressed the feeling of regret and said that they knew the rules and just forgot to use it where necessary.

In the case of Question 2, most participants in the PE group claimed that they have carefully read the passages and tried their best to use the underlined expressions in their own writing. All the interviewed participants in the NF group said that they looked over their errors and tried to make corrections. When further asked for their options about CF, $90 \%$ of them have expressed a clear preference for indirect feedback-- that is, an error called to the student's attention but left for the student to correct.

In the case of Question 3, in both treatment groups most of the interviewed participants said that they consciously reminded themselves to use the third person singular form in the error correction test, but not in the speeded dictation test where they used this inflectional morpheme by feeling or just because they heard the sound of "-s" in the tape.

\subsection{Summary of the Results}

In sum, the results vis-a-vis the research questions are presented as follows:

$R Q$ 1: Do positive evidence and negative feedback have an effect on Chinese learners' acquisition of the third person singular form?

Both treatment groups performed much better than the control group in the error correction Posttest 1 and speeded dictation Posttest $1 \& 2$, suggesting that the two types of input can facilitate the acquisition of the third person singular form.

$R Q$ 2: Is there any difference in the efficacy that positive evidence and negative feedback have on L2 acquisition of this inflectional morpheme?

In the case of the error correction and speeded dictation tests, no significant difference was found between the two treatment groups in either Posttest 1 or Posttest 2, indicating that the two input types had the same effects on the acquisition of this inflectional morpheme.

\section{Discussion}

In terms of the first research question, the results indicate that both positive evidence and negative feedback had an effect on scores in the error correction and speeded dictation tests. This finding suggested that both input types can benefit the acquisition of the third person singular form. Thus, this study not only made a stand for the established role of positive evidence, but also provided further evidence for the controversial role of negative feedback in facilitating L2 development. The rationale lending support for the effectiveness of negative feedback in L2 learning rests on various theoretical bases. The most notable is the Noticing Hypothesis. Schmidt (2001) stated that it is only through conscious attention that input can be converted into learners' intake and he further concluded that noticing is a prerequisite for language learning. Gass and Varonis (1994) likewise related the importance of noticing to the process of SLA by emphasizing that when learners are aware of the gap between what they can produce and what they need to produce, as well as between what they produce and what target language speakers produce, such an awareness would trigger a modification of their current interlanguage knowledge. In light of this, by arousing learners' conscious attention to linguistic forms, according to Gass (1997), negative feedback enables them to restructure their interlanguage that deviates from the target language, and ultimately promotes the process of L2 acquisition. To put it another way, negative feedback functions as a noticing facilitator that assists learners to bridge the gap between their interlanguage and the target language.

Furthermore, the NF group in the current study was given indirect feedback, that is, an error called to the student's attention but left for the student to correct. This approach might invite L2 writers to engage in guided learning and problem-solving (Lalande, 1982) and, as a result, promote the type of reflection on existing knowledge or partially internalized knowledge that is more likely to foster long-term acquisition of the target structure. Actually, empirical evidence for the beneficial effect of indirect feedback on L2 development was found in some previous studies. Lalande's (1982) study of 60 German intermediate foreign language learners reported an advantage for indirect feedback over direct feedback (i.e., explicit correction provided by the teacher or another reader), but the observed between-group difference in accuracy improvement was not statistically 
significant. In a similar vein, Ferris and Helt's (2000) study of 92 learners also found that the effect of indirect feedback was superior to direct error correction. In light of these results, L2 writing researchers maintained that indirect feedback could yield more beneficial results than direct feedback for it requires learners to engage themselves in a more profound form of language processing by promoting self-reflection, attention, and noticing, which ultimately helps to foster long-term acquisition (Ferris \& Roberts, 2001)

In terms of the second research question, the results indicate that the two input types had the same effects on the acquisition of the third person singular form. This finding did not corroborate the findings of some previous input studies situated in the oral context (Ayoun, 2001; Iwashita, 2003; Leeman, 2003; Long el at., 1998) which reported that negative feedback (viz., recast) is more beneficial for the acquisition of some grammatical features than positive evidence. One of the possible reasons for these inconsistent results is that the present study made a clear distinction between positive evidence and negative feedback. In the previous comparative studies, negative feedback was delivered in the form of recasts. Actually, recasts contain both negative evidence and positive evidence (Egi, 2007). Thus, the superior facilitative role of negative feedback (viz., recast) found in the previous studies might be the result of overlying efficiency of negative evidence and positive evidence. Secondly, the positive evidence given in the previous studies was provided implicitly, whereas the salience of positive evidence was enhanced in the present study by underlining the use of the target structure, which might promote learners' conscious attention to linguistic forms and therefore facilitate the acquisition of the target structure. Lastly, the comprehension of positive evidence in the present study was immediately followed by an output task, which may trigger alignment between input and output as learners strive for comprehension of input and use what has been comprehended for production. The coupling of comprehension with production in the present study may not only lead to correct L2 production but also enable learners to extend what they acquire from the input to a new context, and therefore promote L2 acquisition of the third person singular form.

\section{Conclusion}

The present study was designed to compare the relative effectiveness of positive evidence and negative feedback situated in the written context on L2 acquisition of the third person singular form. The results showed that these two input types can facilitate the acquisition of the target structure to the same extent. This finding on the one hand made a stand for the established role of positive evidence in language acquisition, and on the other hand contributed further evidence of the role of negative feedback generally and written negative feedback specifically for L2 acquisition. In the present study negative feedback (viz., indirect feedback) can help learners notice the mismatch or gap between their interlanguage output and the target language in terms of the third person singular form, and further encourage learners to take more responsibility for their own progress.

This study was limited in several ways. First, the target structure is the third person singular form whose grammatical rules had been mastered by learners before the treatment. Therefore, it cannot be assumed that the current conclusion can be generalized to other more complex grammatical structures or new linguistic knowledge. In other words, the present study is far from enough to account for the whole picture of the role of negative feedback and positive evidence in L2 acquisition. Second, the study was a short-term study, lasting for only seven weeks. A long-term study might have produced more reliable and robust evidence of the role of these two types of input in L2 development. It should be noted that short-term studies run the risk of overestimating the effectiveness of negative evidence and underestimating the effects of positive evidence. Therefore, well-designed longitudinal studies would provide more insight into the current issue. Third, the error correction and speeded-dictation tests were used to measure learners' knowledge of the target structure. However, it was generally assumed that learners used their explicit knowledge to a greater extent in these tasks because they allow for controlled processing and monitoring for accuracy (Shintani \& Ellis, 2013). Therefore, it may be necessary for future studies to make use of the time-pressured writing task or spontaneous oral task to assess learners' implicit knowledge.

\section{Acknowledgements}

This research was supported by a grant from the China National Social Science Foundation (14CYY018), an MOE project (12JJD740006) of the Center for Linguistics and Applied Linguistics, Guangdong University of Foreign Studies, a Guangdong High-level Personnel Project (312-GK131036), and a Guangdong Higher Education Reform Project (GDJG20141098).

\section{References}

Ayoun, D. (2001). The role of negative and positive feedback in the second language acquisition of the passé compose and imparfait. Modern Language Journal, 85, 226-243. http://dx.doi.org/10.1111/0026-7902.00106 
Bailey, N., Madden, C., \& Krashen, S. (1974). Is there a "natural sequence" in adult second language learning? Language Learning, 24, 235-243. http://dx.doi.org/10.1111/j.1467-1770.1974.tb00505.x

Blom, E., Paradis, J., \& Duncan, T. S. (2012). Effects of input properties, vocabulary size, and L1 on the development of third person singular $-s$ in child L2 English. Language Learning, 62, 1-30. http://dx.doi.org/10.1111/j.1467-9922.2012.00715.x

Dulay, H., \& Burt, M. (1974). Natural sequences in child second language acquisition. Language Learning, 24, 37-53. http://dx.doi.org/10.1111/j.1467-1770.1974.tb00234.x

Egi, T. (2007). Interpreting recasts as linguistic evidence: The role of linguistic target, length, and degree of change. Studies in Second Language Acquisition, 29, 511-537. http://dx.doi.org/10.1017/S0272263107070416

Ellis, N., \& Sagarra, N. (2010). The bounds of adult language acquisition: Blocking and learner attention. Studies in Second Language Acquisition, 32, 553-580. http://dx.doi.org/10.1017/S0272263110000264

Ellis, R. (1988). The effects of linguistic environment on the second language acquisition of grammatical rules. Applied Linguistics, 9, 257- 274. http://dx.doi.org/10.1093/applin/9.3.257

Ferris, D. R., \& Helt, M. (2000). Was Truscott right? New evidence on the effects of error correction in L2 writing classes. Paper presented at the AAAL Conference, Vancouver, BC.

Ferris, D. R., \& Roberts, B. (2001). Error feedback in L2 writing classes: How explicit does it need to be? Journal of Second Language Writing, 10, 161-184. http://dx.doi.org/10.1016/S1060-3743(01)00039-X

Gass, S. (1997). Input, interaction, and the second language learner. Mahwah, NJ: Lawrence Erlbaum Associates.

Gass, S. (2003). Input and interaction. In C. Doughty \& M. Long (Eds.), The handbook of second language acquisition (pp. 224-225). MA: Blackwell.

Gass, S., \& Varonis, E. (1994). Input, interaction and second language production. Studies in Second Language Acquisition, 16, 283-302. http://dx.doi.org/10.1017/S0272263100013097

Haznedar, B. (2001). The acquisition of the IP system in child L2 English. Studies in Second Language Acquisition, 23, 1-39. http://dx.doi.org/10.1017/S0272263101001012

Inagaki, S., \& Long, M. (1999). The effects of implicit negative feedback on the acquisition of Japanese as a second language. In K. Kanno (Ed.), Studies on the acquisition of Japanese as a second language (pp. 9-30). Amsterdam: Benjamins.

Ionin, T., \& Wexler, K. (2002). Why is 'is' easier than 's'? Acquisition of tens/agreement morphology by child L2 English learners. Studies in Second Language Acquisition, 18, 95-136.

Iwashita, N. (2003). Negative feedback and positive evidence in task-based interaction: differential effects on L2 development. Studies in Second Language Acquisition, 25, 1-36. http://dx.doi.org/10.1017/S0272263103000019

Jiang, N. (2004). Morphological insensitivity in second language processing. Applied Psycholinguistics, 25, 603-634. http://dx.doi.org/10.1017/S0142716404001298

Johnson, J., \& Newport, E. (1989). Critical period effects in second language learning: The influences of maturational state on the acquisition of English as a second language. Cognitive Psychology, 21, 60-99. http://dx.doi.org/10.1016/0010-0285(89)90003-0

Lalande, J. F. (1982). Reducing composition errors: An experiment. Modern Language Journal, 66, 140-149. http://dx.doi.org/10.1111/j.1540-4781.1982.tb06973.x

Lardiere, D. (1998). Case and tense in the "fossilized" steady state. Second Language Research, 14, 1-26. http://dx.doi.org/10.1191/026765898674105303

Larsen-Freeman, D. (2009). Teaching and testing grammar. In M. Long \& C. Doughty (Eds.), The handbook of language teaching (pp. 518-544). UK: John Wiley \& Sons.

Leeman, J. (2003). Recast and second language development: Beyond negative evidence. Studies in Second Language Acquisition, 25, 37-63. http://dx.doi.org/10.1017/S0272263103000020

Long, M. H., Inagaki, S., \& Ortega, L. (1998). The role of implicit negative feedback in SLA: Models and recasts in Japanese and Spanish. Modern Language Journal, 82, 357-371. 
http://dx.doi.org/10.1111/j.1540-4781.1998.tb01213.x

Mackey, A. (2007). Introduction to the relationship between conversation and second language acquisition. In A. Mackey (Ed.), Conversational interaction in second language acquisition: A collection of empirical studies (pp. 379-403). Oxford: Oxford University Press.

Mito, K. (1993). The Effects of Modeling and Recasting on the Acquisition of L2 Grammar Rules. Unpublished manuscript. University of Hawai'i at Manoa.

Ortega, L., \& Long, M. H. (1997). The effects of models and recasts on the acquisition of object topicalization and adverb placement by adult learners of Spanish. Spanish Applied Linguistics, 1, 65-86.

Paradis, J., Rice, M., Crago, M., \& Marquis, J. (2008). The acquisition of tense in English: Distinguishing child second language from first language and specific language impairment. Applied Psycholinguistics, 29, 689-722. http://dx.doi.org/10.1017/S0142716408080296

Perkins, K., \& Larsen-Freeman, D. (1975). The effect of formal language instruction on the order of morpheme acquisition. Language Learning, 25, 237- 243. http://dx.doi.org/10.1111/j.1467-1770.1975.tb00243.x

Philp, J. (1999). Interaction, Noticing and Second Language Acquisition: An Examination of Learner's Noticing of Recasts in Task-based Interaction. Unpublished Ph.D. dissertation. University of Tasmania.

Rabie, S. R. (1996). Negative Feedback, Modeling, and Vocabulary Acquisition in Task-based Interaction. Unpublished Master's thesis, University of Hawai'i at Manoa.

Schmidt, R. (2001). Attention. In P. Robinson (Ed.), Cognition and second language instruction (pp. 3-32). Cambridge: Cambridge University Press.

Shapira, R. (1978). The non-learning of English: Case study of an adult. In E. Hatch (Ed.), Second language acquisition (pp. 246-255). Rowley, MA: Newbury House.

Shintani, N., \& Ellis, R. (2013). The comparative effect of direct written corrective feedback and metalinguistic explanation on learners' explicit and implicit knowledge of the English indefinite articles. Journal of Second Language Writing, 22, 286-306. http://dx.doi.org/10.1016/j.jslw.2013.03.011

Truscott, J. (1996). The case against grammar correction in L2 writing classes. Language Learning, 46, 327-369. http://dx.doi.org/10.1111/j.1467-1770.1996.tb01238.x

Truscott, J. (1999). The case for "The case against grammar correction in L2 writing classes": A response to Ferris. Journal of Second Language Writing, 8, 111-122. http://dx.doi.org/10.1016/S1060-3743(99)80124-6

Truscott, J. (2009). Arguments and appearances: A response to Chandler. Journal of Second Language Writing, 18, 59-60. http://dx.doi.org/10.1016/j.jslw.2008.09.001

Wang, C. (2011). An analysis of three L2 teaching preferences in light of an efficient route to L2 learning. Foreign Language Teaching and Research, 4, 540-549.

Wei, L. (2000). Unequal election of morphemes in adult second language acquisition. Applied Linguistics, 21, 106-140. http://dx.doi.org/10.1093/applin/21.1.106

\section{Copyrights}

Copyright for this article is retained by the author(s), with first publication rights granted to the journal.

This is an open-access article distributed under the terms and conditions of the Creative Commons Attribution license (http://creativecommons.org/licenses/by/3.0/). 